\title{
AVALIAÇÃO DE GENÓTIPOS DE Leucaena spp. NAS CONDIÇÕES EDAFOCLIMÁTICAS DE SÃO CARLOS, SP: I. CARACTERIZAÇÃO FENOTÍPICA E AVALIAÇÃO AGRONÔMICA
}

\author{
A.C.P. de A. PRIMAVESI; A.R.A. NOGUEIRA; O. PRIMAVESI; R. GODOY; L.A.R. BATISTA; \\ N.J. NOVAES \\ Centro de Pesquisa de Pecuária do Sudeste/EMBRAPA, C.P. 339, CEP: 13560-970 - São Carlos,SP \\ M.S. FRANÇA-DANTAS \\ Centro de Pesquisa Agropecuária dos Cerrados -CPAC/EMBRAPA, C.P. 08-223, CEP: 73301-970-Brasaia,DF
}

\begin{abstract}
RESUMO - Para avaliar genótipos promissores de Leucaena spp., foi instalado experimento em Latossolo Vermelho-Amarelo distrofico, na área da EMBRAPA-CPPSE em São Carlos, situada a 22001'S e 47 ${ }^{\circ} 3^{\prime} \mathrm{W}$, com altitude de $856 \mathrm{~m}$ e média de precipitação anual de $1502 \mathrm{~mm}$. Foram testados os seguintes genótipos: Leucaena leucocephala cr. Texas 1074 (T1), L.leucocephala 29 A9 (T2), L.leucocephala 11 x L.diversifolia 25 (T3), L.leucocephala 11 x L.leucocephala 26 (T4), L.leucocephala 24-19/2-39 X L.diversifolia 26 (T5) e L.leucocephala cv. Cunningham (testemunha). Através das avaliaçz̃es efetuadas durante o período de estabelecimento (15 meses), verificou-se que: a) as plantas de L.leucocephala 24-19/2-39 x L.diversifolia 26 se mostraram mais ramificadas e com maior produção de sementes; b) as plantas de L.leucocephala 11 x L.diversifolia 26 apresentaram a maior produção de matéria seca consumível; c) os materiais apresentaram brotação após o corte, semelhante ou inferior à testemumha.
\end{abstract}

Descritores: Leucaena spp., avaliação de genótipos, caracterização biologica

\section{EVALUATION OF Leucaena spp. GENOTYPES IN THE EDAPHIC AND CLIMATIC CONDITIONS OF SÃO CARLOS,SP: I. PIENOTYPICAL CHARACTERIZATION AND AGRONOMICAL EVALUATION}

\begin{abstract}
To test promising genotypes of Leucaena spp., selected in a breeding program, an experiment was conducted in a distrofic Red-Yellow Latossol, at the experimental station of EMBRAPA/CPPSE, São Carlos,SP, located at $22^{\circ} 01^{\prime}$ and $47^{\circ} 53^{\prime} \mathrm{W}$, altitude of $856 \mathrm{~m}$ and with a mean annual precipitation of $1502 \mathrm{~mm}$. The following genotypes were tested: L.leucocephala cv. Texas 1074 (T1), L.leucocephala 29 A9 (T2), L.leucocephala 11 x L.diversifolia 25 (T3), L.leucocephala 11 x L.diversifolia 26 (T4), L.leucocephala 24-19/2-39 x L.diversifolia 26 (T5) and L.leucocephala cv. Cunningham (control). Evaluations were performed during the establishment period (fifteen months) and it was concluded that: a) the plants of L.leucocephala 24-19/2-39 x L.diversifolia 26, with early flowering, were the most branched and presented the greatest seed yield; b) the plants of L.leucocephala $11 \mathrm{x}$ L.diversifolia 26, showed the greatest edible dry matter yield; c) the genotypes presented similar or worse growth, than the control, after each harvest.
\end{abstract}

Key Words: Leucaena spp., evaluation of genotypes, biological characterization.

\section{INTRODUÇÃO}

Nas regiões tropicais, durante a época seca do ano, ocorrem deficiências acentuadas em forragens para a alimentação animal. A leucena, por possuir um sistema radicular profundo e por produzir forragem de excelente qualidade nutritiva (alto teor de proteína nas folhas) e boa palatibilidade aos animais, vem se constituindo em uma das alternativas mais importantes para a agropecuária (VILELA \& PEDREIRA, 1976).

Trabalhos de SEIFFERT (1982), mostraram que a leucena não cresce bem em solos ácidos, com alto teor de alumínio e deficientes em cálcio, molibdênio e zinco e que $\mathrm{o}$ melhor desenvolvimento das plantas se consegue com $\mathrm{pH}$ próximo ao neutro. 
Objetivando selecionar genótipos de Leucaena spp., tolerantes às condições adversas de solo de cerrados, iniciou-se em 1982 no Centro de Pesquisa Agropecuária dos Cerrados (CPACEMBRAPA), um programa de melhoramento desta espécie. Os genótipos que se destacaram neste trabalho foram avaliados em outras condições ecológicas dentro das regiões dos cerrados, sendo - CPPSE de São Carlos um desses locais.

O presente trabalho visa apresentar resultados de avaliações efetuadas durante $o$ período de estabelecimento (15 meses), as quais, foram: ramificação de parte aérea, desenvolvimento, início de florescimento, produção de sementes e produção de matéria seca após o corte.

\section{MATERIAIS E MÉTODOS}

O experimento foi instalado em Latossolo Vermelho-Amarelo distrófico, na EMBRAPA/ CPPSE de São Carlos, situada a $22^{\circ} 01^{\prime}$ 's e $47^{\circ}$ $53 \mathrm{~W}$, com altitude de $856 \mathrm{~m}$, e média de precipitação anual de $1502 \mathrm{~mm}$.

As características químicas do solo onde foi instalado o experimento encontram-se na TABELA 1.

Antes da instalação, a área foi adubada com $450 \mathrm{~kg} / \mathrm{ha}$ de superfosfato simples, $100 \mathrm{~kg} / \mathrm{ha}$ de $\mathrm{KCl}$ e $25 \mathrm{~kg} / \mathrm{ha}$ de FTE Br-12. Não foi aplicado calcário, pois pretendia-se uma saturação por bases de $25 \%$.

Os genótipos usados foram: Leucaena leucocephala cv. Texas 1074 (T1); L. leucocephala 29 A9 (T2); L.leucocephala $11 \times$ L.diversifolia 25 (T3); L. leucocephala $11 \times$ L.diversifolia 26 (T4); L. leucocephala 24-19/2-39 x L. diversifolia 26(T5); L. leucocephala cv. Cunningham (C)-testemunha.

$O$ delineamento experimental foi $o$ de blocos ao acaso com três repetições. As parcelas apresentaram 4 linhas de $7 \mathrm{~m}$ de comprimento, espaçadas de $2 \mathrm{~m}$ entre as linhas. A área útil abrangia os $5 \mathrm{~m}$ medianos das duas linhas centrais.

A semeadura foi realizada em $08 / 02 / 89$, com 20 sementes viáveis por metro linear, a uma profundidade de $3 \mathrm{~cm}$. As sementes foram previamente escarificadas com água a $80^{\circ} \mathrm{C}(2$ minutos) e inoculadas com inoculante específico. A emergência ocorreu 12 dias após o plantio. Aos 100 dias após a instalação foi feito desbaste, deixando-se aproximadamente 5 plantas por metro linear.
Para a avaliação do desenvolvimento, foi determinada a altura média de 10 plantas a cada três meses. $O$ início do florescimento foi registrado quando $25 \%$ das plantas de uma parcela apresentavam flores. A produção de sementes foi avaliada pelo total de sementes produzidas no período de estabelecimento na área útil dos 3 blocos $\left(60 \mathrm{~m}^{2}\right)$. Determinou-se o número de plantas ramificadas dentro da área útil da parcela $e$ avaliou-se a percentagem de ramificação.

Após 15 meses (período de estabelecimento) foi efetuado um corte a $30-40 \mathrm{~cm}$ do solo. Após o corte, foram avaliados: a produção de matéria seca, o percentual de hastes, folhas $\mathrm{e}$ vagens em relação à parte consumível (hastes + folhas + vagens) e a capacidade de rebrota.

A capacidade de rebrota foi avaliada visualmente após o primeiro corte, dentro dos seguintes critérios: 1. Péssima: menos que $50 \%$ da testemunha; 2. má: 50 a $90 \%$ da testemunha; 3 . regular: semelhante a testemunha; 4 . boa: 10 a $50 \%$ a mais que a testemunha; 5 . excelente: mais que $50 \%$ da testemunha.

\section{RESULTADOS E DISCUSSÃo}

Os dados de altura das plantas são apresentados na TABELA 2.

As plantas dos tratamentos $\mathrm{T} 2, \mathrm{~T} 3$ e $\mathrm{T} 4$, na época 3, mostraram o maior desenvolvimento $(40,31$ e $36 \%$ superiores, respectivamente, à testemunha C) e as do tratamento T5, o menor (18\% inferior à testemunha $\mathrm{C}$ ).

As plantas do tratamento T5 foram precoces, pois iniciaram o florescimento em setembro 1989, as do tratamento T1, T4 e C apresentaram florescimento intermediário (novembro 1989) e as dos tratamentos T2 e T3, registraram florescimento tardio (abril 1990). Considerando-se haver queda na produção de forragem após o florescimento, o florescimento tardio é uma característica extremamente desejável.

Sendo a leucena utilizada para corte ou pastejo, genótipos com porte arbustivo são mais convenientes. Entretanto, verificou-se que as plantas de porte arbustivo (T1, T5 e C) apresentaram florescimento precoce, e as de porte ereto (T2, T3 e T4), florescimento tardio, o que também foi constatado por Gray (apud Brewbaker et al., 1972) mas, no entanto, essas épocas de florescimento são herdadas independentemente do hábito de crescimento. 
TABELA 1. Características químicas do solo.

\begin{tabular}{|c|c|c|c|c|c|c|c|c|c|}
\hline \multirow{2}{*}{$\begin{array}{l}\text { Prof. } \\
\text { (cm) }\end{array}$} & \multirow{2}{*}{$\begin{array}{c}\mathrm{pH} \\
\mathrm{CaCL}_{2}\end{array}$} & \multirow{2}{*}{$\frac{\text { P resina }}{\mathrm{ug} / \mathrm{cm}^{3}}$} & \multirow{2}{*}{$\begin{array}{l}\text { M.O. } \\
(\%)\end{array}$} & $\mathbf{K}$ & $\mathrm{Ca}$ & $\mathbf{M g}$ & $\mathrm{H}+\mathrm{Al}$ & CTC & \multirow{2}{*}{$\begin{array}{l}\mathrm{V} \\
(\%)\end{array}$} \\
\hline & & & & \multicolumn{5}{|c|}{$\mathrm{meq} / 100 \mathrm{~cm}^{3}$} & \\
\hline $0-30$ & 4,8 & 3 & 2,0 & 0,13 & 0,8 & 0,07 & 3,6 & 4,6 & 22 \\
\hline $30-60$ & 4,4 & 1 & 1,9 & 0,10 & 0,6 & 0,04 & 3,8 & 4,5 & 16 \\
\hline
\end{tabular}

TABELA 2. Altura das plantas (cm) em 3 épocas do período de estabelecimento

\begin{tabular}{|c|c|c|c|c|c|c|}
\hline \multirow[t]{2}{*}{ Tratamentos } & \multicolumn{2}{|c|}{$\begin{array}{l}\text { Época } 1 \text { (07.11.89) } \\
\text { (9 meses após plantio) }\end{array}$} & \multicolumn{2}{|c|}{$\begin{array}{l}\text { Época } 2 \text { (08.02.90) } \\
\text { (1 anos após plantio) }\end{array}$} & \multicolumn{2}{|c|}{$\begin{array}{l}\text { Época } 3 \text { (10.04.90) } \\
\text { (14 meses após plantio) }\end{array}$} \\
\hline & $(\mathrm{cm})$ & $(\%)$ & $(\mathrm{cm})$ & $(\%)$ & (cm) & $(\%)$ \\
\hline T1 & $88 c^{*}$ & 96 & $197 \mathrm{bc}$ & 94 & $247 \mathrm{~b}$ & 97 \\
\hline $\mathrm{T} 2$ & $133 \mathrm{ab}$ & 145 & $277 \mathrm{a}$ & 132 & $357 \mathrm{a}$ & 140 \\
\hline T3 & $121 \mathrm{~b}$ & 131 & $260 a$ & 124 & $333 a$ & 131 \\
\hline T4 & $141 a$ & 153 & $270 a$ & 129 & $347 a$ & 136 \\
\hline T5 & $91 \mathrm{c}$ & 99 & $179 \mathrm{c}$ & 86 & $209 c$ & 82 \\
\hline C Testemunha & $92 \mathrm{c}$ & 100 & $209 \mathrm{~b}$ & 100 & $255 b$ & 100 \\
\hline
\end{tabular}

- Valores seguidos da mesma letra dentro de cada coluna não diferem estatisticamente ( $P>0,05$, Tukey).

TABELA 3 - Peso das sementes produzidas durante - período de estabelecimento $(14 / 12 / 89$ a $31 / 05 / 90)$.

\begin{tabular}{ccc}
\hline \hline \multirow{2}{*}{ Trata- } & \multicolumn{2}{c}{ Produção de Sementes } \\
\cline { 2 - 3 } mentos & Gramas/60 $\mathrm{m}^{2}$ & $\begin{array}{c}\text { \% Relação } \\
\text { Testemunha }\end{array}$ \\
\hline T1 & 425,8 & 392 \\
T2 & 34,2 & 31 \\
T3 & 3,5 & 3 \\
T4 & 126,4 & 116 \\
T5 & 849,5 & 781 \\
C & 108,7 & 100 \\
\hline \hline
\end{tabular}

TABELA 4 - Percentagem média de ramificação.

\begin{tabular}{ccc}
\hline \hline $\begin{array}{c}\text { Trata- } \\
\text { mentos }\end{array}$ & $\begin{array}{c}\text { Ramificação } \\
(\%)\end{array}$ & $\begin{array}{c}\text { \% em relação à } \\
\text { Testemunha }\end{array}$ \\
\hline T1 & $63 \mathrm{ab}$ & 93 \\
T2 & $56 \mathrm{ab}$ & 82 \\
T3 & $38 \mathrm{~b}$ & 56 \\
T4 & $52 \mathrm{ab}$ & 76 \\
T5 & $73 \mathrm{a}$ & 107 \\
C & $68 \mathrm{ab}$ & 100 \\
\hline \hline
\end{tabular}

Valores seguidos da mesma letra dentro de cada coluna, não diferem estatisticamente $(P>0,05$, Tukey). 
TABELA 5 - Produção de matéria seca total, folhas, vagens,talos finos, talos grossos e parte consumível no corte de uniformização $\mathrm{em} \mathrm{kg} / \mathrm{ha}$ e percentagem em relação à testemunha.

\begin{tabular}{|c|c|c|c|c|c|c|c|c|c|c|c|c|}
\hline \multirow{2}{*}{$\begin{array}{l}\text { Trata- } \\
\text { mentos }\end{array}$} & \multicolumn{2}{|c|}{ PMST } & \multicolumn{2}{|c|}{ PMSF } & \multicolumn{2}{|c|}{ PMSV } & \multicolumn{2}{|c|}{ PMSTF } & \multicolumn{2}{|c|}{ PMSTG } & \multicolumn{2}{|c|}{ PCCP } \\
\hline & $\mathbf{k g} / \mathbf{h a}$ & $\%$ & $\mathrm{~kg} / \mathrm{ha}$ & $\%$ & $\mathrm{~kg} / \mathrm{ha}$ & $\%$ & kg/ha & $\%$ & $\mathrm{~kg} / \mathrm{ha}$ & $\%$ & kg/ha & $\%$ \\
\hline T1 & $6096 \mathrm{~b}$ & 104 & $1826 \mathrm{bc}$ & 141 & $1166 \mathrm{ab}$ & 129 & $291 \mathrm{c}$ & 49 & $2775 b$ & 91 & $3319 b$ & 118 \\
\hline $\mathrm{T} 2$ & $10730 \mathrm{a}$ & 183 & $3203 \mathrm{ab}$ & 242 & $259 b$ & 29 & $918 \mathrm{ab}$ & 153 & $6352 a$ & 209 & $4380 \mathrm{ab}$ & 155 \\
\hline T3 & 9227ab & 158 & 2784abc & 211 & 91b & 10 & 886ab & 148 & $5471 \mathrm{a}$ & 180 & $3761 \mathrm{ab}$ & 133 \\
\hline T4 & $11010 \mathrm{a}$ & 188 & $3643 a$ & 276 & $651 \mathrm{ab}$ & 72 & $1080 \mathrm{a}$ & 180 & $5634 a$ & 185 & $5373 a$ & 190 \\
\hline T5 & $5508 b$ & 94 & $1057 \mathrm{c}$ & 80 & $1259 a$ & 139 & $712 \mathrm{ab}$ & 119 & $2440 \mathrm{~b}$ & 80 & $3029 b$ & 107 \\
\hline C & $5854 b$ & 100 & $1321 b c$ & 100 & $904 \mathrm{ab}$ & 100 & $599 b$ & 100 & $3036 b$ & 100 & $2820 \mathrm{~b}$ & 100 \\
\hline
\end{tabular}

Valores seguidos da mesma letra dentro da mesma coluna não diferem estatisticamente $(P>0,05$, Tukey)

PMST $=$ Produção de matéria seca total PMSTF $=$ Produção de matéria seca talos finos PMSF $=$ Produção de matéria seca folhas; PMSTG = Produção de matéria seca talo grosso PMSV = Produção de matéria seca vagens $\mathrm{PCCP}=$ Produção de matéria seca parte consumível.

A produção de sementes foi avaliada para se verificar a possibilidade da multiplicação local dos genótipos. Assim, a TABELA 3 mostra a produção de sementes no período de estabelecimento (15 meses) dos diversos genótipos de leucena.

As plantas do tratamento T5, precoces, apresentaram a maior produção de sementes seguidas das plantas do tratamento T1. Verifica-se que apenas T2 e T3 não apresentaram boa capacidade de produção de sementes.

A capacidade de ramificação normalmente está associada à produção de forragem. A TABELA 4 apresenta a percentagem média de ramificação dos diversos materiais de leucena. Constatou-se que as plantas do tratamento T5 apresentaram a ramificação mais intensa $(7 \%$ a mais que a testemunha) e as do tratamento T3 a menos intensa (44\% a menos que a testemunha). As plantas dos tratamentos T2 e T4 apresentaram porte ereto.

Considerandoa variação da população nas parcelas como sendo uma covariável na análise de variância, obteve-se as seguintes medias estimadas para produção de matéria seca total, de folhas, de vagens, de talos grossos e da parte consumível (TABELA 5).

Verifica-se que durante o periodo de estabelecimento, as plantas dos tratamentos T2 e
T4 apresentaram a maior produção de matéria seca total (83 e $88 \%$, respectivamente, superior à testemunha) e as do tratamento T4 a maior produção de matéria seca consumível $(90 \%$ superior à testemunha). As plantas do tratamento T4 registraram a maior produção de matéria seca de folhas e de talos finos $(176 \%$ e $80 \%$, respectivamente, superior à testemunha). As plantas dos tratamentos T2, T3 e T4 apresentaram a maior produção de matéria seca de talo grosso, devido ao fato desses genótipos apresentarem porte ereto. Os rendimentos obtidos variaram de 5,5 t/ha a 11 $\mathrm{t} / \mathrm{ha}$, respectivamente para os tratamentos T5 e T4.

Estudos sobre produtividade em leucena têm sido conduzidos por vários pesquisadores, os quais têm encontrado grandes variações nos rendimentos de matéria seca. A produção de matéria seca depende da fertilidade, da disponibilidade de água do solo, das variedades cultivadas e do manejo adotado. Rendimentos variam de 1,5 t/ha a 20 t/ha, segundo KLUTHCOUSKI (1982), HUTTON \& BONNER (1960), BODGAN (1977).

SEIFFERT \& THIAGO (1983), conseguiram, em regime de corte anual no início da estação seca, rendimentos de matéria seca de 5,6 a 9,0 tha.

Na TABELA 6 encontram-se as médias da participação percentual da parte consumível. 
TABELA 6 - Médias de participação percentual das partes consumíveis.

\begin{tabular}{ccccc}
\hline \hline & PCC $^{-}$ & FP & VP & TFP \\
Tratamentos & $(\%)$ & $(\%)$ & $(\%)$ & $(\%)$ \\
\hline T1 & $53 \mathrm{ab}^{*}$ & $31 \mathrm{a}$ & $17 \mathrm{ab}$ & $5 \mathrm{a}$ \\
T2 & $41 \mathrm{bc}$ & $30 \mathrm{a}$ & $3 \mathrm{~b}$ & $9 \mathrm{a}$ \\
T3 & $40 \mathrm{c}$ & $30 \mathrm{a}$ & $0,2 \mathrm{~b}$ & $10 \mathrm{a}$ \\
T4 & $49 \mathrm{abc}$ & $32 \mathrm{a}$ & $7 \mathrm{~b}$ & $10 \mathrm{a}$ \\
T5 & $58 \mathrm{a}$ & $19 \mathrm{a}$ & $27 \mathrm{a}$ & $12 \mathrm{a}$ \\
C & $51 \mathrm{abc}$ & $22 \mathrm{a}$ & $18 \mathrm{ab}$ & $11 \mathrm{a}$ \\
\hline \hline
\end{tabular}

-Valores seguidos da mesma letra dentro da mesma coluna não diferem estatisticamente $(P>0,05$, Tukey) PCC $=$ Percentagem das partes consumíveis secas; FP = Percentagem de folhas secas; $\mathrm{VP}=$ Percentagem de vagens secas; TFP $=$ Percentagem de talos finos secos.

TABELA 7 - Capacidade de rebrota (nota) após o primeiro corte.

\begin{tabular}{clll}
\hline \hline Tratamentos & Bloco 1 & Bloco 2 & Bloco 3 \\
\hline T1 & regular & má & regular \\
T2 & má & má & má \\
T3 & boa & regular & regular \\
T4 & regular & má & má \\
T5 & má & má & má \\
C & testemunha & & \\
\hline \hline
\end{tabular}

A percentagem da parte consumível variou de 40 a $58 \%$ de matéria seca produzida, o que também foi verificado por SEIFFERT \& THIAGO (1983).

As plantas do tratamento $\mathrm{T} 5$ apresentaram a maior participação percentual da parte consumível e as do tratamento T3, a menor.

Os genótipos não variaram quanto à participação porcentual das folhas e talos finos. Já para vagens, o genótipo T5 apresentou a maior participação percentual.
As plantas dos tratamentos $\mathrm{T} 1, \mathrm{~T} 2, \mathrm{~T} 3 \mathrm{e}$ $\mathrm{T} 4$, apresentaram a maior produção de matéria seca de folhas em relação a de vagens e talos finos e as do tratamento $\mathrm{T} 5$, a maior produção de vagens.

Na TABELA 7 encontra-se a avaliação da capacidade de rebrota após o primeiro corte.

\section{CONCLUSÕES}

1) As plantas de L.leucocephala 24-19/2-39 × $L$. diversifolia 26, com florescimento precoce, 
mostraram-se mais ramificadas e com maior produção de sementes.

2) As plantas que registraram maior desenvolvimento foram as de: L.leucocephala 29 A9, $L$. leucocephala $11 \times$ L.diversifolia $25, L$. leucocephala $11 \times$ L.diversifolia 26.

3) As plantas de Leucaena leucocephala $11 \mathrm{x}$ Leucaena diversifolia 26 , apresentaram a maior produção de matéria seca consumível $(90 \%$ a mais em relação à testemunha).

4) Dentre os materiais avaliados, nenhum deles apresentou brotação superior à espécie utilizada como testemunha (Cunningham).

\section{REFERENCIAS BIBLIOGRÁFICAS}

BODGAN, A.V. Tropical pasture and fodder plants. New York Longman. 465p., 1977. Apud Garcia, R. Banco de proteína. In: CONGRESSO BRASILEIRO DE PASTAGENS E SIMPÓSIO SOBRE MANEJO DE PASTAGEM, 8. Piracicaba, 1986. Anais. Piracicaba, FEALQ, 1986.

GRAY, S.G. Inheritance of growth habit and quantitative characters in intervarietal crosses of Leucaena leucocephala (Lam.) de Wit. Australian Journal of Agricultural Research, v.18, p.71-76, 1967. Apud BREWBAKER, J.L.; PLUCKNETT, D.L.; GONZALES, V. Varietal variation and yield trial of Leucaena leucocephala (Koa Haole) in Hawaii. University of Hawaii, 1972. v.166, p.1-29.
HUTTON, E.M.; BONNER, I. Dry matter and protein yields in four strains of Leucaena glauca Benth. Journal of the Australian Institute Agricultural Science, v.26, p.276, 1960. apud Garcia, R. Banco de proteína. In: CONGRESSO BRASILEIRO DE PASTAGENS E SIMPÓSIO SOBRE MANEJO DE PASTAGEM, 8., Piracicaba, 1986. Angis. Piracicaba, FEALQ, 1986.

KLUTHCOUSKI, J. Leucena: alternativa para a pequena e média agricultura. 2.ed. Goiania, EMBRAPACNPAF, 1982. 12p. (EMBRAPA-CNPAF. Circular Técnica, 6).

SEIFFERT, N.F. Low performance of Leucaena Penu type on Central Brasil Oxisols. Hawaii. Leucaena Research Reports, v.3, p.7-8, 1982.

SEIFFERT, N.F.; THIAGO, K.R.L. Legumineira: Cultura forrageira para produçāo de proteína. Campo Grande, EMBRAPA-CNPGC, 1983. 52p. (EMBRAPA-CNPGC. Circular Técnica, 13).

VILELA, E.; PEDREIRA, J.V.S. Efeitos de densidades de semeadura e níveis de adubação nitrogenada no estabelecimento de Leucaena leucocephala (Lam.) de Wit. Boletim da Indústria Animal, v.33, n.2, p.251-280, 1976.

Enviado para publicação em 25.01 .93

Aceito para publicação em 20.09.93 